\title{
Automatic Protection System of Neutral Wire-broken Based on Supply-side Protection
}

\author{
Guangwei Luo, Wenjun Zhang and Jialin Yin \\ Sichuan Engineering Technical College, De Yang, China \\ lgw@scetc.net
}

\begin{abstract}
Neutral wire is one form of distribution lines for faults. Neutral wire will cause the neutral potential shift and increase the voltage, which may endanger electrical appliances and persons. The entire existing neutral wire automatic protection device are to protect the load side and there are not protective measures on the supply side. Has load protection side. The research of the protection system is that Bi-directional zero-phase method will be taken to obtain the voltage and current square wave after the emergence of neutral wire of the load side. Then each wave is sampled and the phase difference is calculated by microcomputer control system, which will be combined with the neutral current change detection to cut off the power of supply side and achieve the automatic protection. The system can well achieve automatic protection of neutral wire on the supply side.
\end{abstract}

Keywords: neutral wire; supply-side protection; phase difference; bi-directional zerophase; single-chip microcomputer

\section{Introduction}

Neutral wire break is one of the forms of power supply line fault. In low voltage threephase four wire system TN-S power line, it would cause that the load side of the neutral point potential deviation, the voltages on single-phase load are unequal and part of the electricity equipment burnt because of overvoltage after neutral wire break, it may endanger electric appliances and personal safety when the situation is serious [1-3]. At present, the automatic protection of power system aims at the voltage current phase shift, voltage fluctuation and harmonic enlargement that caused by the power grid fault, it utilizes microcomputer intelligent control system to realize automatic protection to the power of phase difference, voltage fluctuation and harmonic change after detecting them [5-6]; we cut off the load after neutral wire break to protect the neutral wire break fault in low voltage power supply system, protection device is installed at the load side, it has no automatic protection at power supply side, system continues to power supply, and there is an electric shock and other security risks.

The protection device mainly researches the oad-line reduction of power supply side to realize automatic protection after neutral wire break in low-voltage three-phase four wire system TN-S power supply system. Detecting the power supply voltage, current and neutral current through voltage and current transformer; then enter into single-chip microcomputer detection and control system after bidirectional zero-phase filter shaping. If current phase shift that caused by neutral line break, single chip microcomputer control system calculates the phase changes before and after the neutral line break, and judge it combining with the change of the neutral line current, analyzing whether the neutral wire is broken or not. If appearing the neutral wire break fault, issuing a fault control signal, cutting off the power supply, and realizing automatic protection in power supply side. The device is applied in 
bright lighting engineering in motor control company, after neutral line is accidentally disconnected, to realize the automatic protection of the power supply side after neutral wire break reliably.

\section{Neutral Wire Break}

The neutral line is public loop of three-phase power. The function of the neutral line is to maintain the balance of three phase voltage and supply power circuit for the single phase load at the same time when star connection of load is asymmetric and there is circuit through the neutral wire.

Power supply system adopts three-phase four wire power to supply, and the load adopts star to connect, it is shown in Figure 1.

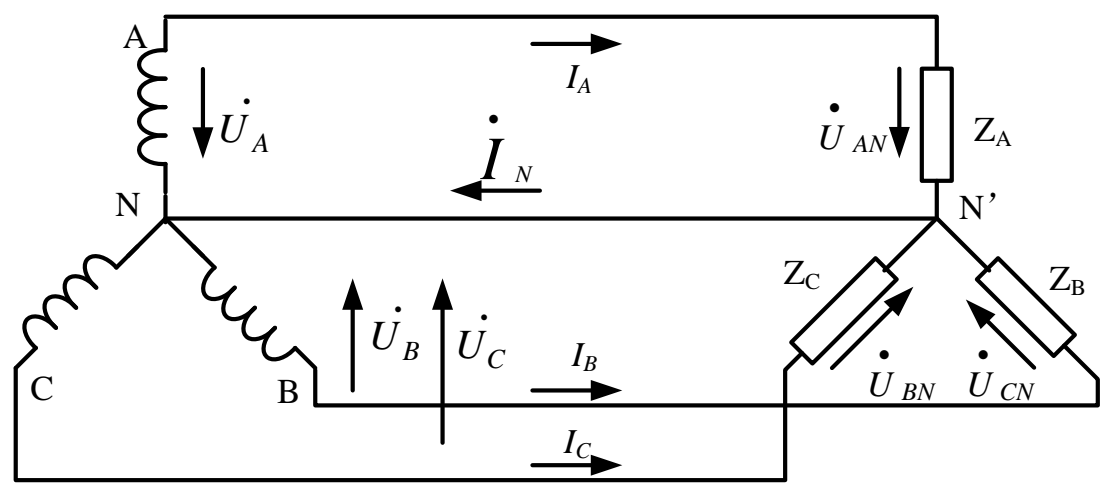

Figure 1. Connection Diagrammatic Sketch of Three-phase Four-line Power Supply System

\subsection{Three-phase Load Balancing}

When the three-phase load equilibrating, if the neutral line is broken, we could obtain the following equations due to the power supply is symmetrical.

$$
\begin{aligned}
& \dot{I}_{A}+\dot{I}_{B}+\dot{I}_{C}=0 \\
& I_{A}=I_{B}=I_{C}=\frac{U}{|Z|}
\end{aligned}
$$

Three-phase currents are equal, same to the phase, so they have no effect on the operation of the system.

\subsection{Three-phase Load Unbalancing}

When the three-phase load isn't equilibrating, it is shown in Figure 2. There is no central Line current if the center line disconnects, but we could obtain the following equation.

$$
I_{A^{\prime}}+I_{B^{\prime}}+I_{C^{\prime}}=0
$$

According to Meermann theorem:

$$
U_{N N^{\prime}}=\frac{U_{A} \bullet Y_{A}+U_{B} \bullet Y_{B}+U_{C} \bullet Y_{C}}{Y_{A}+Y_{B}+Y_{C}} \neq 0
$$




$$
\begin{aligned}
& \dot{U}_{A N^{\prime}}=\dot{U}_{A N}-\dot{U}_{N N^{\prime}} \\
& \dot{I}_{A^{\prime}}=\frac{\dot{U}_{A N^{\prime}}}{Z_{A}}=\frac{U_{A N^{\prime}}}{\left|Z_{A}\right|} \angle \varphi_{A} \\
& \dot{U}_{B N^{\prime}}=\dot{U}_{B N}-\dot{U}_{N N^{\prime}} \\
& \dot{I}_{B^{\prime}}=\frac{\dot{U}_{B N^{\prime}}}{Z_{B}}=\frac{U_{B N^{\prime}}}{\left|Z_{B}\right|} \angle \varphi_{B} \\
& \dot{U}_{C N^{\prime}}=\dot{U}_{C N}-\dot{U}_{N N^{\prime}} \\
& \dot{I}_{C}=\frac{\dot{U}_{C N^{\prime}}}{Z_{C}}=\frac{U_{C N^{\prime}}}{\left|Z_{C}\right|} \angle \varphi_{C}
\end{aligned}
$$

$\varphi_{A}, \varphi_{B}$ and $\varphi_{C}$ are not equal in above three current vector equations, the phase difference between current and voltage of power supply side will have great changes after neutral wire break.

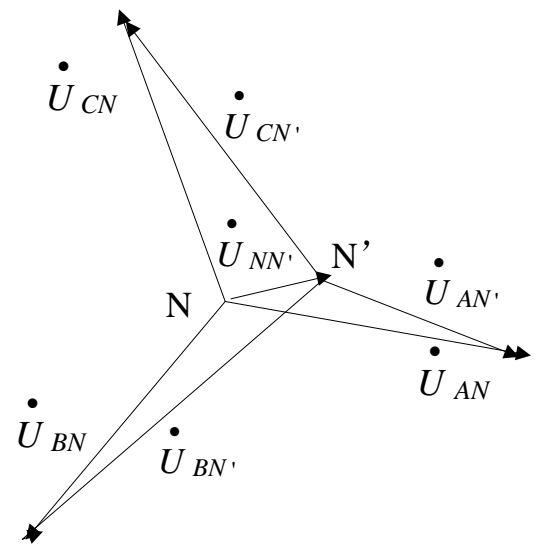

\section{Figure 2. Vector Diagram behind the Neutral Line Interruption}

For the three-phase unbalanced load, the migration of neutral point, the imbalance between the voltages of three-phase load and the larger changes to the phase of current and voltage would be caused by the neutral wire break, it also affects the normal operation of equipment, so the neutral wire break line protection is particularly important.

\section{Design of Neutral Line Breaking Protection Device}

Neutral line broken protection adopts protection in power supply side, it is shown in Figure 3. 


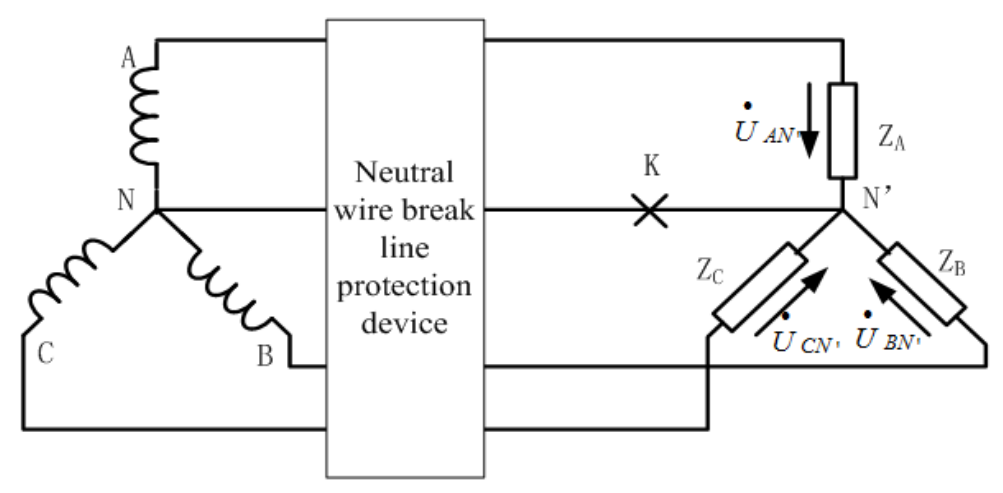

Figure 3. Protection Schematic Diagram of the Neutral Line Interruption

If $\mathrm{K}$ point appears the neutral wire break, then device protection power side cut off the power supply, avoiding the three-phase unbalanced load supply voltage that caused by the neutral line break and exceed the rated voltage and burn load.

\subsection{Protection Device Design}

The neutral line breaking protection device is composed by single chip microcomputer, filter shaping circuit, protect the driver circuit, voltage transformer and current transformer, it is shown in Figure 4. MCU completes the calculation of the phase of phase difference before and after the break, then judges whether the neutral line is broken according to the phase change; three voltage transformer detect the three phase voltage, four current transformers were used to detect the phase current and neutral current, potentiometer RP is used to set the three-phase unbalanced load factor.

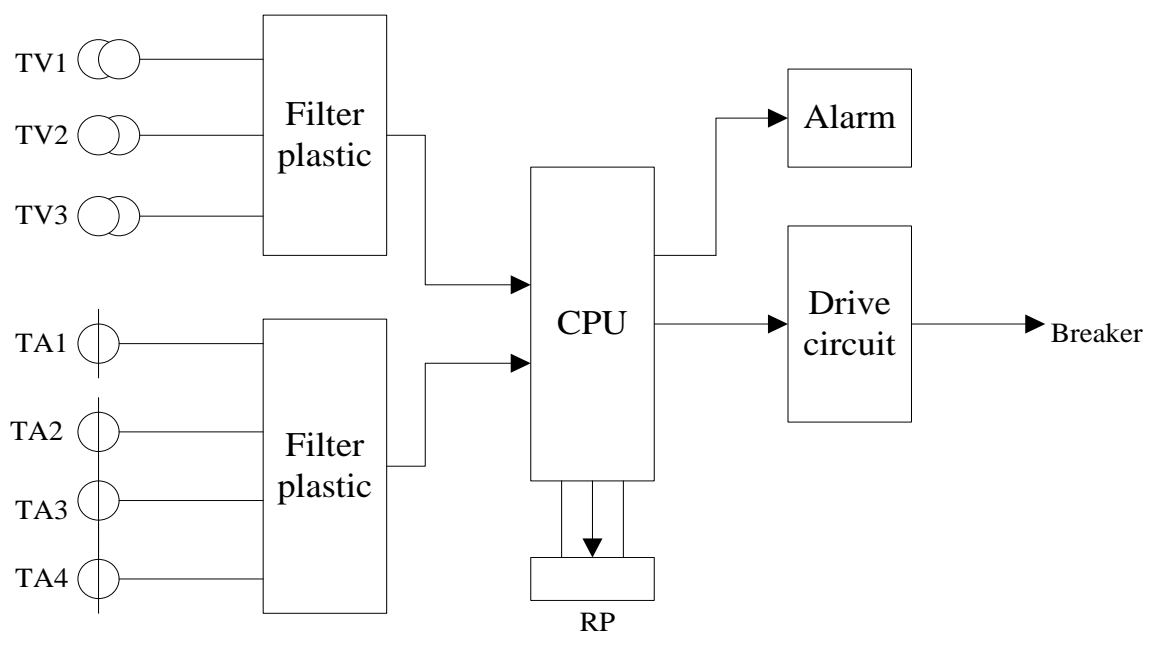

Figure 4. Structure Diagram of Protection Device

\subsection{Protection Principle}

According to the three-phase unbalanced load equations, we could know that if the neutral line is broken, it would cause the migration of neutral point when the threephase load is unbalanced. We utilize current transformer to detect the neutral current 
and utilize current transformer and voltage transformer to detect the phase difference between the three phase current and voltage before and after bolting in the device. If there is a neutral line break, the neutral line does not exist current in power supply side, the phase difference of current and voltage changes in power supply side at the same time, the judgment rule is shown in table 1. If the disconnect system automatically cut off the power supply, it would issue a warning at the same time.

Table 1. Judge Rules of Neutral Wire

\begin{tabular}{ccc}
\hline Neutral current & Phase difference & Conclusion \\
No & Be & Neutral wire break \\
No & No & Three-phase load balancing \\
$\mathrm{Be}$ & No & Unbalanced load, Neutral line isn't broken \\
$\mathrm{Be}$ & $\mathrm{Be}$ & Serious unbalanced load, Neutral line isn't \\
& & broken \\
\hline
\end{tabular}

\subsection{Phase Difference Detection}

Phase detection is mainly to detect voltage and current through voltage and current transformer, to get the corresponding rectangular square wave signal by shaping filter and bi-directional zero crossing discriminator circuit, it is shown in figure 5 .

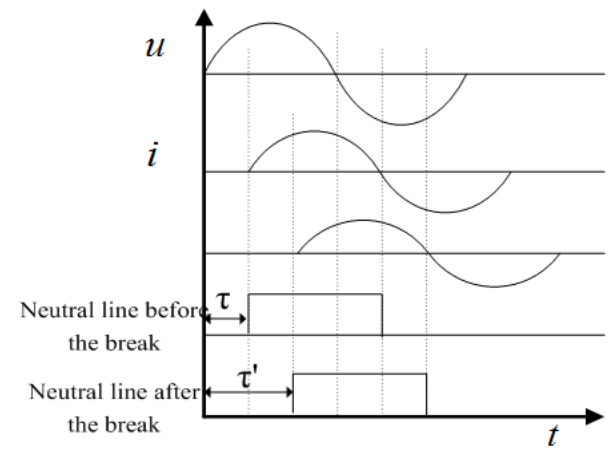

Figure 5. Schematic Diagram of Phase Detection

From Figure 5, we could obtain the phase difference changes of the voltage and current, neutral line break before the phase difference is $\tau$, neutral line break before the phase difference is $\tau^{\prime}$, the change of the phase difference before and after the break is $\Delta \theta=\tau^{\prime}-\tau$.

Collecting the length of time to the voltage current signal maintenance through MCU external interrupt input, calculating the phase difference of neutral line break before and after, detecting the size of the current in the neutral line at the same time, and then determining whether the neutral line break or not according to the judge rules in table 1 , to realize the automatic protection function. 


\section{Conclusion}

Glorious lighting engineering in the motor control company, causing single lamp high voltage and burn lamps because of neutral accidentally disconnected in the three phase four wire TN - S system, there are no burned lamps and lanterns after using the protection device, realizing the automatic protection about the power supply side after neutral line break reliably.

\section{References}

[1] R. Wen, "Low Voltage Power Distribution System in the Zero Line Fault Causes and Treatment [J]", Power Supply Technology Application, vol. 10, no. 175, (2012).

[2] B. Li, F. Jin and Z. Li, "Voltage Circuit of Neutral Line Broken Wires of Recessive Fault Identification and Its Impact [J]”, China Journal of Electrical Engineering, vol. 13, no. 33, (2013), pp. 179-185.

[3] F. Guo, "Three-phase Four-wire Power Supply System Neutral [J]", Physics Bulletin, vol. 10, (2011), pp. 115-118.

[4] X. Jiao, Z. Wu and J. Wang, "Analysis of Zero Sequence Protection Issues in the Application of Grid [J]”, Inner Mongolia Electric Power Technology, vol. 5, no. 29, (2011), pp. 1-4.

[5] X. Chen, P. Cai and W. Shi, "On-line Detection of Phase Based on Single Chip Microcomputer [J]. Measurement and Control Technology, vol. 9, no. 21, (2002), pp. 15-16.

[6] X. Zhang, R. Wu and Z. Guo, "Discussion on TN_S low Voltage Power Distribution Line Neutral Line Breaking Protection Device [J]”, Electrical Engineering Technology, vol. 8, (2012), pp. 1-3.

[7] T. Jiang, "Three-phase Four-wire System Neutral Line Disconnection Reason Hazards and Preventive Measures of the Power Supply System [J]”, Machine Tool Electrical Appliance, vol. 4, (2006), pp. 44-45.

[8] Y. Wang, Z. Li and Y. Wang, "Realization of Three Phase Four Wire System Power Supply System Neutral Line Broken Wires to Protect the Research of Intelligent Device [J]", Low Voltage Electrical Apparatus, vol. , (2011), pp.18-22.

[9] Y. Liu, "Three-phase Four Wire Line Breaking Protection Circuit [J]", Journal of Liaoyang College of Petrochemical Technology, vol. , no. 17, (2001), pp. 41-43.

[10] T. Wang, "Three-phase Four Wire System with Neutral Wire Break Detection Method [J]", Ningxia Machinery, vol. 1, (2009), pp. 61-62.

[11] D. You and Y. You, "Neutral Line Potential Shift Circuit Breaker Protection and Its Application [J]", Electrical Engineering Application, vol. 1, (1999), pp. 21-27.

[12] S. Chen and Z. Yao, "Voltage Loop Neutral Effect on Zero Sequence Direction Protection Analysis and Preventive Measures [J]", Power System Protection and Control, vol. 14, no. 36, (2008), pp. 8082.

[13] X. An, "Analysis of Low Loltage Three-phase Four Wire Power Supply System Neutral Point and the Neutral Line [J]", Journal of Development, vol. 12, (2012), pp. 107-108.

[14] F. Zhang, Z. Ma and Y. Liu, "Low Voltage Power Factor Monitoring and Automatic Compensation System Based on Single Chip Microcomputer [J]", Chinese Waterway, vol. 7, no. 7, (2007), pp. 156157.

[15] X. Feng, "Accurate Digital Measurement Method of Power Factor [J]", High Voltage Electrical Apparatus, vol. 4, no. 45, (2009), pp. 90-93.

[16] Z. Li, "Neutral Wire Break Fault Protection for Low Voltage Distribution System [J]", Northeast Electric Power Technology, vol. 5, (1998), pp. 59-61.

[17] L. Yi, "Neutral Wire Break Fault Protection [J]", Heilongjiang Science and Technology Information, vol. 14, no. 23, (2004).

[18] G. Li, Y. Xiao and Y. Cao, "Protective grounding fault in the low voltage distribution system [J]", Shanxi building, vol. 1, no. 35, (2009), p. 209. 